\title{
Traceability as a tool aiding food safety assurance on the example of a food-packing plant
}

\author{
Dorota Miarka ${ }^{1} \cdot$ Bogumiła Urbańska ${ }^{1}$ Jolanta Kowalska ${ }^{1}$ (i)
}

Received: 16 July 2018 / Accepted: 31 December 2018 / Published online: 9 April 2019

(c) The Author(s) 2019

\begin{abstract}
Enabling the possibility of "tracing" the route of a food product is a legal requirement for all participants of the food chain. It allows identifying and monitoring traffic and use of batches of raw materials, waste products, and finished products in the entire supply chain. The case study concerning a traceability system was conducted during BRCv7 (British Retail Consortium, Issue 7) audit made for packaged soybean oil. The analysis was based on the SOP (Standard Operating Procedure), HACCP (Hazard Analysis and Critical Control Points) procedure and records, including those concerning CCP (Critical Control Point), as well as the data from internal software Manufacturing WHM (WebHost Manager) Inquiries Version 5.2.8. and Traceability 2.1.0. for tracing batches of raw materials, additives, finished products, and clients. Verification revealed nonconformity in routine tests of the system, which was put on the list of corrective actions. Their correction was a prerequisite for meeting requirements of the standard and for system improvements. The corrective actions included complementation of the operational procedure for traceability of production and related documents with the records of supervision and verification of raw materials and packaging. The changes were introduced in the control procedure of machines and appliances in order to reduce the loss incurred while during packing oil. The employees were trained with regard to the changes introduced in the procedures, and the effectiveness of these actions was confirmed, which proved the necessity of the corrective actions undertaken.
\end{abstract}

Keywords Traceability $\cdot$ BRC $\cdot$ Food safety $\cdot$ HACCP

\section{Introduction}

Safety is the key criterion of food which underlies the most important element of demand-consumer's trust. Consumer preferences are driven by sensory traits, availability, attractiveness, and price of products. Food-conscious consumers more and often choose products from reliable sources. They search for information about products and check the

Jolanta Kowalska

jolanta_kowalska@sggw.pl

Dorota Miarka

dorota_miarka@sggw.pl

Bogumiła Urbańska

bogumila_urbanska@sggw.pl

1 Department of Biotechnology, Microbiology and Food Evaluation, Division of Food Quality Evaluation, Faculty of Food Sciences, Warsaw University of Life Sciences (SGGW), ul. Nowoursynowska 159c, 02-787 Warsaw, Poland manufacture process and the source of raw materials. They expect the product bought to meet current standards. A food product entails safety and a set of conditions that need to be satisfied and actions that need to be taken at all stages of food production and sales in order to protect human lives and health, and even though this safety is imposed by legal regulations, it is also an element of the awareness and responsibility of a manufacturer. There are many tools for safety assurance, and their effectiveness is verified by individual entities according to their internal needs and possibilities. Tracing the route of all components and participants of a product manufacture process, referred to as traceability, is one of the methods supporting safety assurance. It results from Regulation No. 178/2002 section IV art. 18, but is also mentioned in fundamental recommendations of various food standards, e.g., BRC [3, 6]. BRC extends the requirements provided for in Regulation No. 178/2002, by for example, obliging manufacturers to check the effectiveness of traceability tests. Clause 3.9 of the BRCv7 standard concerns the need to apply traceability systems-it is one of the basic 
requirements whose fulfillment enables certification. The standard provides for the system verification by the internal audit (BRCv7 clause 3.4), but also specifies the time limit (maximum $4 \mathrm{~h}$ ) for the identification of the batches of raw materials and ingredients, recipients, and the history of the product in question. This standard has been established in response to recent food "scandals" (BSE, bovine spongiform encephalopathy), loss of consumer trust, and necessity of controlling both the safety and quality of food products delivered by suppliers [8]. The British Retail Consortium has elaborated an international BRC standard (global standard), which covers not only legal regulations (GMP—good manufacturing practice; GHP_-good hygienic practice; HACCP), but also elements of management (taken from the ISO 9001 standard), which are extended with additionally developed guidelines, the major objective of which is to assure consumers of the safety of foods they purchase. This standard is common in Great Britain, but a growing interest in the BRC certificate is also expressed by many companies worldwide, as a tool enabling verification of the offered and manufactured food [7]. All requirements of the BRC standard were classified into seven sections, and non-conformity with any of the fundamental goals, having an impact on food safety, results in certificate granting rejection or certification suspension.

The basic elements of the BRC standard, Issue 7 (BRCv7), making the core of the system are:

a. senior management commitment (BRCv7 c.1.0),

b. the food safety system-HACCP (BRCv7 c.2.0),

c. food safety and quality management system: documentation, registers, records, internal audits, monitoring suppliers, specification, traceability, corrective actions, and incident management (BRCv7 c. 3.0),

d. site standards concerning factory layout, product flow and segregation, building work requirements, maintenance of equipment, chemical and physical product contamination control, raw material and intermediates handling, preparation, processing, packing and storage areas, control actions types, and procedures (BRCv7 c. 4.0),

e. product control (BRCv7 c. 5.0),

f. process control (BRCv7 c. 6.0),

g. staff personal hygiene control (BRCv7 c. 7.0).

The aim of this study was to analyze and evaluate traceability testing as an element of food safety management in the context of verification and internal improvement on the example of soybean oil packing. The route of all components and participants of the process was traced in the framework of a BRC food audit (in version 7 in force during the audit) in a food industry plant specializing in packing edible oils. Traceability effectiveness was analyzed on the example of soybean oil packed in 15-1 metal barrels labeled with an internal symbol of the plant containing the production date, the best-before date, and the code of a metal sheet supplier. In the analyzed production plant, the packaging was formed from steel and galvanized metal sheet. Traceability test was conducted based on the Standard Operating Procedure (SOP) and a checklist developed by a BRC auditor. Data were collected with internal software implemented at the plant Manufacturing WHM Inquiries Version 5.2.8. and Traceability 2.1.0 software developed for tracing finished products and clients. Apart from the traceability test, the audit analyzed food safety HACCP system compliance with legal regulations. Descriptive and graphical methods were used to prepare this report. According to the approved schedule, a 2-day BRC audit was conducted by one auditor, and a product traceability test was evaluated on the first day of the audit in compliance with the guidelines of the BRC standard and completed within $3.5 \mathrm{~h}$.

\section{BRC audit: a traceability checklist}

Standard Operating Procedure (SOP) concerning the traceability concerns the records of all production stages, with consideration given to the acceptance of deliveries of raw materials and packaging, and dispatch of finished products. Apart from standard procedures, the SOP records contained the description of activities conducted during routine control tests of oil packing such as: oil tank filter control, raw material transmission line control, drum line quality control, control of the seal of drum metal container, and finished product weight control. These procedures and actions were applied to analyze the product traceability process, which assured the quality and safety of the finished product. The documentation and control registers were evaluated during the traceability test. To enable the BRC audit, a traceability checklist was prepared by an expert auditor (Table 1). The list of exemplary documents was completed with information from the SOP checklist and with the specified order of particular actions in the product identification procedure.

For the purpose of providing evidence during the BRC traceability test, apart from paper records, the Manufacturing WHM Inquiries Version 5.2.8 software was used, which provided the required data of packaging, raw materials, and the full list of ingredients and amount of the finished product. These data are collected on the basis of the Working Orders produced by the system, which are used as internal batch numbers assigned to each half product or product series. They enable identification of batches of raw materials and packaging and tracing them on the basis of purchase orders. Another software used as a source of evidence was Traceability 2.1.0 especially designed for tracing. It contains the list of all finished products and clients that received the batch numbers on the basis of the "one step backwards 
Table 1 Exemplary documentation of traceability audit required by the auditor

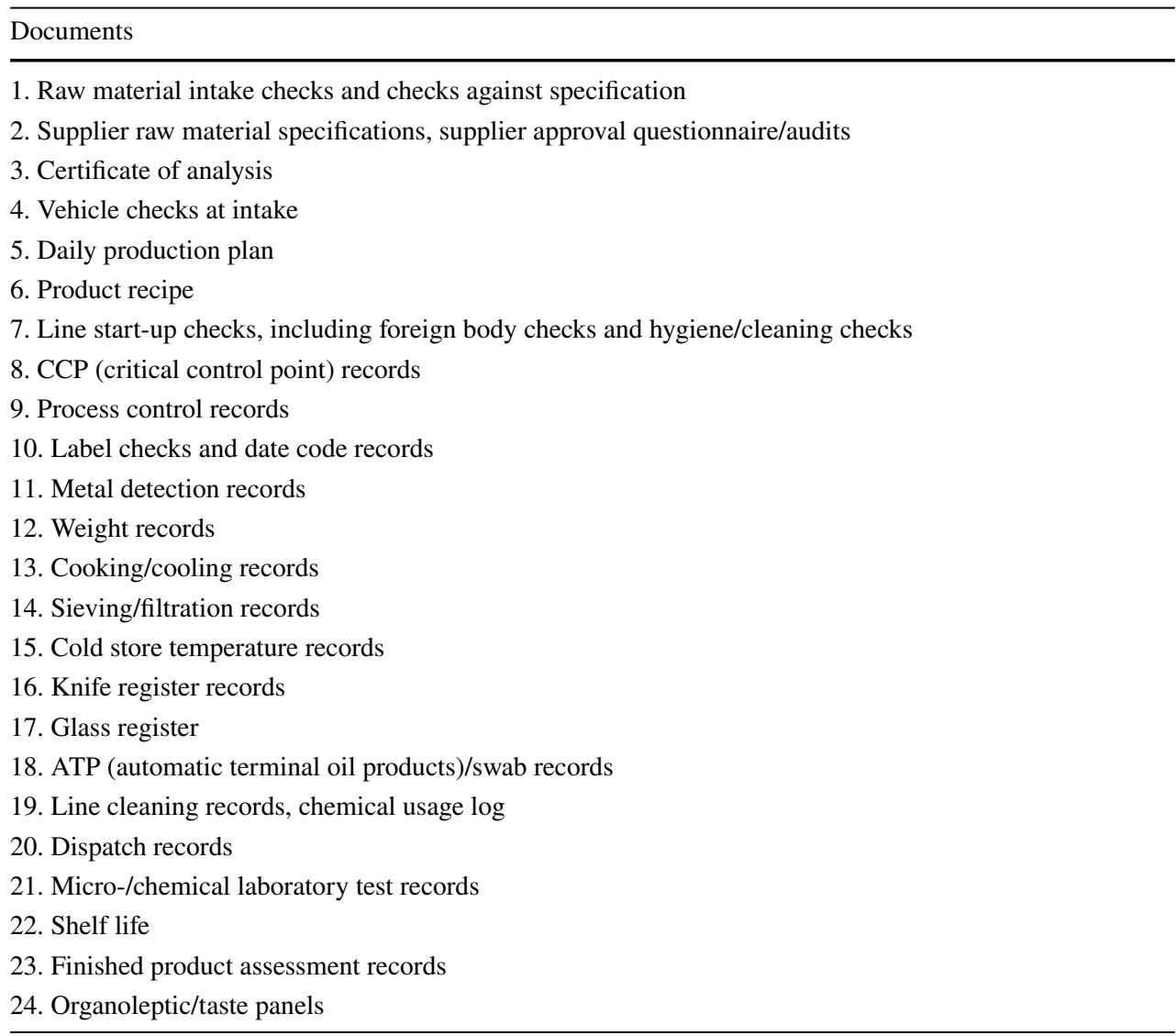

and one step forwards" tracing principle. All the changes in the pallet such as relocating or removing drums due to their damage or joining the pallets of drums from different flows are also recorded. The search can be done on the basis of such criteria as the batch number, ingredient, or raw material code. They can be extended to sales and purchase orders. The information can be obtained on the 0-to-4 scale as appropriate. During the traceability test, it was found out that in the event of software breakdown batches can be identified on the basis of paper records drawn up by line technicians or machine operators.

\section{Food traceability test}

\section{Identification of the finished product}

While identifying soybean oil with the ascribed code, the auditor determined the total production size. Identification test was conducted with the use of the internal Traceability 2.1.0. system and the paper records, which were identified according to the codes ascribed (indicated by the system). Identification included the number of soybean oil drums released for sale, the number of pallets on which they were stored, and the number of drums per pallet. The shelf life of the finished product was 24 months. Coding each drum included the best-before-end (BBE) date, i.e., the production date +2 years, according to the Julian calendar and the code of the metal sheet supplier. The number of damaged drums and drums unsuitable for sale, as well as the place where they were stored, were read out from documents. Products subjected to the traceability test were stored in a storehouse of finished products, from where they were dispatched to 10 different clients, including mainly wholesalers and catering units. A minimal order included one whole pallet of oil. Information about the finished product included: product type, oil weight balance of the batch being produced, the number of the barrels produced, the weight of each barrel, and the data from the label. The type of information provided on the dynamic scale of a packing machine screen and oil weight balance is presented in Table 2 .

The oil weight balance presented in Table 2 specifies the amount of raw material necessary to satisfy the production needs, the amount transferred from the tank to the drums, the amount of oil in recycled drums, and the amount of waste oil produced as a result of the drum damage. The difference in the oil mass in this manufacturing process resulted from the breakdown of the packing line (numerous stoppages), as a result of which the oil which was pushed down the line that was suddenly stopped leaked from the filler, which caused loss in 
Table 2 Oil weight balance in the manufacture process

\begin{tabular}{lr}
\hline Oil summary & \multicolumn{1}{l}{$(\mathrm{kg})$} \\
\hline Required & 53226.34 \\
Used out of tank & 53184.00 \\
Rework & 0.00 \\
Waste not lost & 0.00 \\
Total oil used & 53184.00 \\
Difference & -42.34 \\
\hline
\end{tabular}

production. The procedure of handling non-conforming products applied at the plant obligated a production line worker to collect the oil leakage, weigh, mark (with a red label), describe, and store it in an especially designated place in order to prevent its reuse. According to the procedure, a manager checks nonconforming material and sends it for utilization. The soybean oil leakage of the tested batch of the weight $42.34 \mathrm{~kg}$ was secured by the production worker so that it was not reused, in accordance with the relevant procedure, and then it was sent for utilization in accordance with the schedule on the basis of the agreement with the outsourced company. The reason for the stoppages at the production line was a breakdown of the conveyors transmitting the drums down the production line. The corrective and preventive actions were undertaken. The technical failure was fixed by a technical support worker, and a monthly servicing and maintenance of the packing lines was implemented. Each of these actions was recorded in related documents. The above-mentioned preventive measures concerning the packing lines were conducted outside the obligatory working-order tests of the packing lines before starting the production.

\section{Identification of oil}

The raw material is delivered in cisterns, from which it is pumped into tanks at the packing plant. Each delivery has its individual identification number assigned, which is scanned and entered into the internal system. All quantities and details of delivery are specified by the Manufacturing WHM. The analyzed oil was delivered on the same day in three separate batches. For the production purposes of the analyzed soybean batch, on the production day, $63.31 \%$ of the weight of the oil with the same identification number was collected from the storage tanks. Oil traceability stages are depicted in Fig. 1.

Oil used in the production process originated from genetically modified soybean. An anti-saponifying agent was added to the oil in the amount consistent with product specification. The oil and food additives used were identified using respective records from the manufacture process and an efficient logistic management system.

\section{Identification of packaging components}

In order to demonstrate that the backward ("a step backwards") and forward ("a step forwards") tracing system is being developed and proves efficient, one package for contact with foods and its components were traced.

The packaging used to pack the analyzed oil was assembled at the audited plant from the following elements: bottom, drum, and top. All these elements were subjected to quality control according to the binding procedures. The packaging tracing process was conducted with Manufacturing WHM software containing data on bottoms, tops, metal sheet types, and quantities used to assemble the package. Each pallet with package component was labeled with a bar code with the ascribed batch number used for identification. The software displayed the Working Order, exact movement of each pallet, production line, date, and quantity of given out elements (Fig. 2). Data displayed by the system were filtered to confirm the conformity of the material used with the stock and actual usage of the packaging elements.

\section{Identification of suppliers}

An important element of the traceability system is the possibility of indicating suppliers. The audited side uses the Standard Operating Procedure (SOP) for approving suppliers, which not only refers to the approval and classification, but also implements the supplier monitoring system. According to this procedure, suppliers are evaluated using an approval questionnaire or an audit. In the approval process, each material is analyzed in terms of posing risk to food safety as well as its quality and legality. A documented risk assessment is conducted for each group of materials, which takes into account risks associated with their contamination with allergens, presence of foreign bodies, GMO (genetically modified organism), microbiological contamination, chemical contamination (including migration of compounds from the package to the product), and adulterations. The approved suppliers are classified according to the level of risk, provide required documentation according to the fixed schedule, and finally are listed in a supplier register. The suppliers of the raw materials and packaging for the traced oil batch were approved in accordance with the relevant procedure, and the
Fig. 1 Identification of oil used in the production process based on the working order

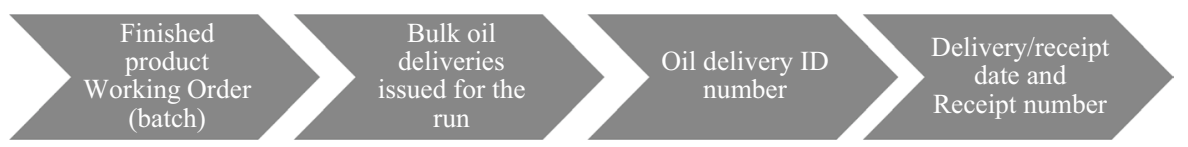




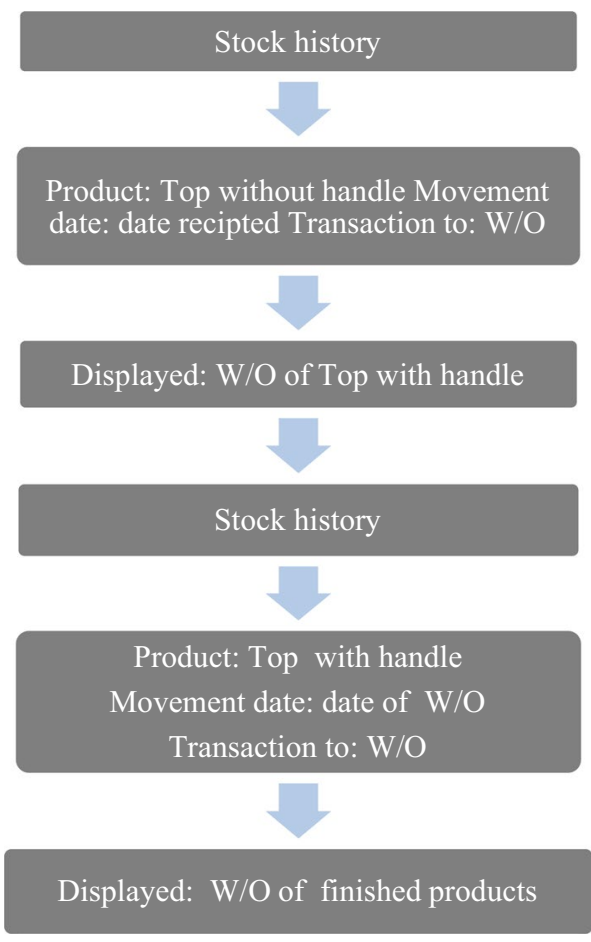

Fig. 2 Stages of finished product tracing with the use of selected components W/O (working order)

analyzed records contained the specification of the oil and the packaging components, i.e., steel sheets, upper drum, light-sensitive metal sheets, and drum top.

\section{Identification of the finished product specification}

Internal software used for traceability purposes displays two specification types: Specification of Production Process and Specification of the Finished Product.

Specification of the Production Process-raw materials, package, and all other components used in the production process have their fixed specifications. Technical data are checked at least once a year, any changes are first approved, and then the specification is updated.

Specification of the Finished Product-this document contains information about the finished product including details of its manufacture process, supplier contact information, number of packaging used, details concerning best-before date, storage conditions, material attributes, instruction manual, and list of components including their suppliers and countries of origin. In addition, it lists all allergens, GMO ingredients, and target consumers (for vegetarians, vegans, koshers, diabetics), as well as product-certifying agency. The nutritional value of the product was presented in compliance with guidelines of the EU Regulation No.1169/2011, including the number of collected samples of the raw material and sampling frequency. Details were also provided concerning the packaging: its type, basic weight, pallet type and color, possibility of using MAP (Modified Atmosphere Packaging), and results of microbiological, physical and chemical tests of the product with their scope and methods used.

\section{Identification: control of production line before its start-up}

Production line control before its start-up included checking of: controlling system, condition of tools, technical condition of machines and appliances, functionality of the production line at its different sections, on-site presence of all parts of the machines including especially nuts and screws, and absence of packaging from previous batch production. These control checks were listed by a technician and a mechanic in the register and verified by a manager before production start-up. The line was cleansed according to a fixed schedule after production and during production stoppages. Due to the packing line breakdown on the test date, it was cleansed four times. Everyday and weekly tasks concerning hygiene were listed in the control sheet which was checked and signed by the assigned manager.

\section{CCP identification}

The manufacture process of the analyzed oil included four Critical Control Points: compliance with specification during delivery receipt (CCP1), oil loading to an appropriate tank during delivery receipt and oil selection for an appropriate production line (CCP2), filter checking (CCP3), and control of the reprocessing process (CCP4). The following monitoring records were presented for each control point, except for reprocessing of the non-conforming product, which was not conducted on that day:

$C C P 1$-identified oil was delivered and unloaded into one storage tank a day before its production date. The volume of oil required for the production process was collected from the storage tank according to the production order.

CCP2 - each activity of opening or closing the tank for the production line was carried out according to a respective procedure, signed by an authorized worker and verified by a shift Manager.

CCP3-filter was checked before and after loading the controlled oil batch. The control sheet contained a completed register with data on filter condition and was handled to the auditor. This document revealed that after one oil loading, a physical hazard was detected in the form of a piece of a rubber gasket, which could have contaminated the material and clogged the oil transmission line. The piece of gasket was sent to the technical department. The following corrective actions were undertaken: The gaskets of the oil transmission line were serviced during unloading into storage tanks and at 
the production line. The cleanliness of the storage tanks was checked after unloading and before reloading them. The note of the non-conformity was transmitted to the supplier of the loaded batch of oil for the purpose of internal cistern control. These actions were aimed at controlling the technical condition of the equipment used for oil transmission as well as eliminating possible future non-conformities by introducing a fortnightly control of gaskets at the oil transmission lines into the procedure of machines and appliances control. The secured foreign body (the piece of gasket) and the records from undertaken corrective actions were presented during the audit.

Verification of the HACCP system included control of $\mathrm{CCP}$ registers. The system, as a whole, is verified periodically by the HACCP team.

\section{Identification of records before finished product release}

Quality Records-it is a production document which is completed once per shift by an assigned worker of the production line and contains information about the weight of the finished product and packaging condition. These records are part of the finished product release documentation.

Weight control-a document subjected to the controlling procedure included records of weight made during the production process. A simulation of the weighing procedure was conducted at the beginning and end of each shift. The mean weight of the product fitted in the fixed percentage range. Records confirm notifications of each deviation from the fixed ranges.

Condition of packaging of the finished product - the presented records show that packaging control before product release included checking the appropriateness of pattern and shade, checking handle location, visual inspection of the binder, and tightness tests. Drums had no dents nor symptoms of damages and were appropriately arranged on the pallet.

\section{Identification: internal audit}

A monthly audit of glassware and plastics was performed by the controller in the test period. A list of all plastic elements needed to be exchanged was sent to the engineering department and included in the repair and conservation schedule. The process compliance audit covered inspections of various aspects of the production and was performed by persons indicated in the schedule. Controlled production areas included: process, documentation, tool inspection, GMP, production, personal protective equipment (PPE), hygiene, trainings, and competence. The total score reached $94 \%$ because the production plant failed to meet two requirements concerning the process which was discovered during the analysis of the documentation of the traceability system tests for one of the products. It was demonstrated that the plant did not conduct the routine "forward" tracing of raw materials and packaging. Corrective actions were undertaken. The plan for corrective actions regarding these non-conformities required procedure update. For this purpose, a subclause was included which provided for the analysis of every document concerning raw materials, from supervising suppliers, verifying specification, transportation, raw material acceptance and storage at the analyzed organization, and assigning all the workers responsible for and implementing all the processes related to raw materials. A similar addition was made in the packaging control. The number of each document concerning raw materials and packaging was entered onto the list of related documents in the traceability procedure.

\section{Discussion}

Traceability is possible thanks to an efficient strategy of marking and tracing all the elements participating in the process. The elements which enabled traceability of soybean oil at the analyzed plant were: the internal operational system, marking documents provided for by the internal procedure, assigning responsibilities, training employees as well as internal and external communication. The audit confirmed the efficiency of the operational system. All the documents, i.e., the procedures for identifying raw materials, controlling the production process, packaging, and the finished product, were identified together with the related documents (registers, control tests, laboratory test results) and proved by the evidence registered with the use of specialist software for tracing raw materials and finished products. The 15-1 batch of soybean oil indicated by the auditor with the specified code, and shelf life was traced. The amount released for sale, its recipients, and the utilized amount were also identified. The oil weight balance of the packed soybean oil was checked. The documents recording the process revealed a raw material loss caused by numerous stoppages of the line transmitting packaging at the filling line. The corrective actions involved extending the procedure by recording oil leaks during each technical stoppage. A regulation was also introduced to control the transmitters every day and maintain them at least once a month. Regular check-ups of transmitting appliances contributed to the reduction of the loss of raw materials, which was confirmed by the production registers on the following days. The suppliers of raw materials and packaging were approved in accordance with the relevant procedure. The specifications of oil, additives, packaging, and finished product were controlled. The plant provides full identification of the components of metal containers, which were possible thanks to the software designed for tracing raw materials, packaging components, packaging, and 
finished products. The data filtration on the basis of production orders allowed for fast tracing of the used raw materials, packaging materials, packaging, and finished products. Complete standard records of the condition of packing lines before starting the oil filling were presented. The test included the conformity of the procedure of accepting raw materials with specification and documentation of the delivered oil concerning the tested batch of raw materials, which confirmed the conformity of the controlled area (CCP1). There was a complete identification of oil with the tested code unloaded and stored. The paper records and the data displayed by the software for tracing raw materials and finished products showed each movement of the analyzed batch of oil on the basis of the identification number assigned. The amount of pumped oil, date, tank numbers, supplier's identification number, and distribution of the tested part of raw materials were read out with special attention to the amount and date of unloading, the tank number from which the raw material was taken, and the number of the oil transmission line. The tested oil batch was pumped into tanks 1 and 2 . The records of hygienic and technical condition of tanks were checked before pumping the oil and after unloading it (the washing record and the technical condition record). All the records of the CCP2 analyzed confirmed its proper supervision. Oil filters from storage tanks 1 and 2 were controlled before pumping the oil and after loading it. The records confirmed the proper supervision of CCP3. The Filter Control Record contained information about physical contamination (a piece of rubber gasket) in filter 2. The piece was removed, and corrective action was introduced in the form of controlling all the gaskets on the transmission lines every 2 weeks, with the relevant entries made in the procedure of the machines and appliances control. The oil-packing plant did not recycle raw materials from the tested batch. Therefore, CCP4 supervision records were not verified. The CCP1, $\mathrm{CCP} 2, \mathrm{CCP} 4$, and $\mathrm{CCP} 3$ registers confirmed the proper supervision of the indicated critical control points. While forming steel drums from the tested batch of raw materials, a worker at the line, which forms packaging checked the drums visually, recorded this activity and also recorded packaging tightness tests. In accordance with the procedure, every 20th barrel was checked for tightness by submerging it into water; any air bubbles emerging from the barrel entailed mandatory control of all previous packaging since the last positive test, correction of tightness plus another control. The records confirmed that all the barrels from the tested batch of oil were checked positively for the seal tightness. Before the beginning of the packing process, $100 \mathrm{ml}$ of the raw material was taken from the production tank for physical and chemical analyses of the oil. The organoleptic features of the material were controlled (color, smell, taste, clarity, and physical contamination). After starting the production, organoleptic features were controlled by taking the material from the line every hour until the end of the packing process. The records of these activities confirmed the proper supervision of the oil-packing process. While packing the tested soybean oil, the weight of the finished product was recorded. At the packing line, each finished packaging had an identification number; the weight of the packaging was recorded by the software for tracing finished products. Moreover, every $15 \mathrm{~min}$, the operator of the production line controlled the weight of the finished product with the control scales and made relevant entries in the records. The production code, the packaging number, and the weight of the finished product were recorded in the register of weight control and conformed with the specification of the finished product. The traceability test included the analysis of the records of the internal audit conducted for glassware and plastics, the records of the indicated CCPs, the GMP, and the GHP. The tools and the documents regarding the personnel hygiene and staff training were inspected, and the records confirmed their proper supervision. One non-conformity was identified during the document analysis, i.e., in the internal audit the plant did not trace "forward" the raw materials and packaging. The corrective actions were undertaken immediately, and the tracing procedure and related documents were complemented with relevant provisions, which provided for the necessity to trace the route of raw materials and packaging as an element of traceability. The list of the related documents connected with the operational procedure was also completed with the numbers of procedures and instructions and related record cards concerning the delivery of raw materials and packaging and their introduction into the process. The staff was trained with reference to the changes in the procedure. The effectiveness of these actions was checked on another product (50 1 of soybean oil) with an internal test after 2 months, which allowed to trace fully raw materials "one step forwards" and "one step backwards." This confirmed the effectiveness of the corrective actions taken. The audit showed that in the event of a breakdown of the software for tracing raw materials and finished products, an effective tracing of the finished product is possible thanks to regular records on paper. Pursuant to BRC guidelines, an internal traceability system of a plant should allow to "monitor all batches of raw materials and packaging and their suppliers, all stages of processing, recipients, and vice versa" [3]. The key element of this systematic approach is implementation of procedures for system monitoring and verification, and implementation of records confirming the performed activities [11, 14, 15]. Effective implementation of the BRC standard within the supply chain may not only reduce potential costs of finished product withdrawal, but may also minimize their adverse effect on consumers by an efficient withdrawal process [9]. The traceability test conducted during the BRC system certification audit showed that since the last audit the plant had won new recipients of 
packed soybean oil, while continuing sales to the old clients. The growing tendency in sales indicates high competitiveness of the tested plant on the market of packed edible oils and its successful cooperation with raw material suppliers and the recipients of the finished product. A well-functioning traceability system strengthens consumer confidence in companies, prevents trade with adulterated foods, enables managing all processes in a company and the supply chain, and finally improves overall effectiveness $[1,5,12]$. Bosona and Gebresenbet [2] claim that benefits from a well-functioning traceability system include better crisis management, use of novel scientific research, and awareness of sustainable agriculture. Effective risk management involves also elimination of non-conforming products and protection against health threats and also against company responsibility and bad reputation $[4,10,13]$. The BRC certificate aims at reducing the number of audits of recipients, minimizing costs resulting from losses and mistakes, and at extending the sales market.

\section{Conclusions}

The BRCv7 certificate renewal audit demonstrated that the audited plant does not trace the used raw materials and packaging during routine traceability simulation. As a result, corrective actions were undertaken, which included updating the Standard Operating Procedure of the traceability process by adding the provisions concerning the ways of marking and storing used and damaged packaging and its elements. In order to check the effectiveness of the corrective actions, within 7 days of the audit the plant conducted an internal TEST, which checked the traceability of the raw materials and packaging used in accordance with post-audit recommendations. Moreover, 2 months after the audit, the plant conducted an internal traceability test for oil packed in 50-1 barrels. The test took $3.5 \mathrm{~h}$ and proved the effectiveness of the updated operational procedure and the usefulness of the software used. The records covered complete "forward" traceability of raw materials and packaging having contact with the product. Once the audit had been completed, the plant obtained score A and was granted the certificate confirming compliance of its internal procedures with BRC standard, meeting legal regulations, and implementing an efficient and effective internal system for offered goods safety management.

\section{Compliance with ethical standards}

Conflict of interest The authors declare that they do not have a conflict of interest.
OpenAccess This article is distributed under the terms of the Creative Commons Attribution 4.0 International License (http://creativeco mmons.org/licenses/by/4.0/), which permits unrestricted use, distribution, and reproduction in any medium, provided you give appropriate credit to the original author(s) and the source, provide a link to the Creative Commons license, and indicate if changes were made.

\section{References}

1. Bezat A, Jastrzębowski S (2011) Traceability in the supply chain in food processing. Logistyka 2:75-84

2. Bosona T, Gebresenbet G (2013) Food traceability as an integral part of logistics management in food and agricultural supply chain. Food Control 33:32-48

3. Global Standard Safety ISSUE 7 (2015) British Retail Consortium, London. http://www.brcglobalstandards.com. Accessed Jan 2015

4. Czarniecka-Skubina E, Nowak D (2012) The tracing system for food traffic and origins a tool of providing customer safety. ZYWN-NAUK TECHNOL JA 5(84):20-36

5. Dabbene F, Gay P, Tortia C (2014) Traceability issues in food supply chain management. Biosyst Eng 120:65-80

6. Hossain-Jany N, Islam R, Mazumder AR, Uddin B (2016) Design and application of hazard analysis critical control point principles for typical frozen vegetables. J Food Saf Hyg 2(1-2):8-14

7. Kawecka A (2014) BRC/IoP standard importance in packaging quality assurance. Prod Eng Arch 3(4):14-17

8. Kumar A, Parappurathu S, Babu SC, Joshi PK (2017) Can better governance improve food security? An assessment of the public food distribution system in Odisha, India. Food Secur 9(6):1433-1445

9. Mattevi M, Jones JA (2016) Traceability in the food supply chain: awareness and attitudes of UK. Food Control 64:120-127

10. n Aung MM, Chang YS (2014) Traceability in a food supply chain: Safety and quality perspectives. Food Control 39:172-184

11. Mortimore S (2000) How to make HACCP really work in practice. Food Control 12:209-215

12. Śmiechowska M (2014) Traceability system in assuring food identification and safety. Ann Acad Med Gedanensis 44:125-132

13. Sokołowski G (2014) Kluczowe element system identyfikacji żywności. The key elements in food traceability system. Logistyka 6:69-71

14. Steinhauserowa I, Borilova G (2015) New trends towards more effective food safety control. Procedia Food Sci 5:274-277

15. Walker E, Pritchard C, Forsythe S (2003) Hazard analysis critical control point and prerequisite programme implementation in small and medium size food businesses. Food Control 14:169-174

Publisher's Note Springer Nature remains neutral with regard to jurisdictional claims in published maps and institutional affiliations. 